\title{
The research of intangible cultural heritage protection based on
} \section{experiential tourism development----Taking Qinhuangdao as an Example}

\author{
Zhang yan \\ Environmental Management College of China, Qinhuangdao, Hebei, 066000
}

Keywords: Intangible cultural heritage protection; experiential Tourism development; Cultural heritage

\begin{abstract}
:
Intangible cultural heritage is the precious wealth of the human civilization, plays a vital role on blood relation of inheriting national culture. Also is the main content in the process of the tourism experience. Experiential tourism development is the only road of intangible cultural heritage protection. Deal with the relationship between protection and development, intangible cultural heritage protection and tourism development can be implemented benign interaction. In this paper, taking Qinhuangdao as an Example, in combination with the current of the tourism development of intangible Cultural Heritage, to discuss how to realize intangible cultural heritage protection in a way of experiential Tourism development

Intangible cultural heritage is an important carrier for the testimony of our history and the Chinese culture, contains the unique Chinese spiritual values, ways of thinking, imagination and cultural awareness, which reflect the vitality and creativity of the Chinese nation. Under the impact of this global trend that the cultural tourism is becoming the demanding core of tourism, the protection and inheritance of intangible cultural heritage, as well as the research on the combination of intangible cultural heritage and tourism are particularly urgent. Particularly tourists involved in the process of tourism activate the traditional culture which has gradually disappeared, Qinhuangdao has a unique intangible cultural heritage, if the rich intangible cultural heritage resources combined with tourism development, and focus on experiential tourism development, find a way of benign interaction in the protection and development, at the same time to promote regional economic development, and also realize the civilization of intangible cultural heritage, so as to achieve an important role of historic preservation
\end{abstract}

\section{Conservation status of the Intangible Cultural Heritage of Qinhuangdao}

Qinhuangdao has a long history with deep culture, and process abundant intangible cultural heritage. Qinhuangdao municipal government issued the "Regulations to strengthen the protection work of intangible cultural heritage for the city" at 2007, Qinhuangdao City Intangible Cultural Heritage Protection Work Leading Group was set up, intangible cultural heritage protection institutions has been basically established in the three districts and four counties. At 2009, Qinhuangdao launched a citywide general survey of intangible cultural heritage, and carried out a systematic and comprehensive statistics for intangible projects in Qinhuangdao. In which, five projects are listed as the national intangible cultural heritage, these are Changli ToYongko, Changli folk songs, Funing wind and drum music, the fairy tales of Meng Jiang $\mathrm{Nu}$, Changli shadow. Jieshishan legends and stories, Funing Taiping drums, Funing Tai Huang Gang, Lulong Boyi \&Shuqi, Sense comes with age, Liguang shooting the tiger, the historical legends of Shang born from Xuan bird, Lulong's vermicelli processing techniques, Qinglong monkey playing stick, Manchu village’s Youngko, 
wind and drum music performed by Renjia Ban in Beidaihe, the story of Xiao Xian writing plaque at Shanhai pass and etc.. These twenty-six projects are elected as provincial intangible cultural heritage. Funing shadow carving, embroidered shoes, paper cutting, Tianmashan fair, techniques of cake making by Boluo leaves , Qinglong tofu, shadow, craftsmanship of "Yang Chang Zi" at Beidaihe, Shanhai pass's Hun Guo, trumpet, Mengjiangnv fair and other fifty-one projects are selected as Municipal Intangible Cultural Heritage. 126 projects are elected as county-level intangible cultural heritage, an intangible cultural heritage spread base of Hebei province is established, 2 representative inheritors of nation-level projects; 16 provincial project representative inheritors; 32 municipal intangible projects representative inheritors.

Recently, Qinhuangdao City Intangible Cultural Heritage Protection Center also specially developed " Interim Measures of assessment for Qinhuangdao intangible cultural heritage declare," " protection work management system for Qinhuangdao intangible cultural heritage ", the protection for the provincial, municipal intangible and other endangered projects will also be strengthen, the loss of the project to further strengthen the protection. Intangible projects collection and exhibition hall of Qinhuangdao City is established, to secure those objects and resources with historical value, artistic value, research value and preserve value to be truly preserved and displayed, and gradually create a good atmosphere for intangible cultural heritage protection and the corresponding travel development.

\section{The relationship between intangible cultural heritage protection and experiential tourism development}

\section{A intangible cultural heritage is an important resource for tourist experience}

Most of the Intangible Cultural Heritage has distinct regional characteristics, will help to enhance the interest of tourism resources, improve the quality of experience for tourists. With increasingly abundant experience of tourists, the demanding of tourists for cultural experience with local characteristics is growing, rooted in living habits of different regions and different groups, intangible cultural heritage with "Living" feature has become an important part of the tourists' experience. As some of the traditional craftsmanship in Qinhuangdao, like craftsmanship of "Yang Chang Zi" at Beidaihe, Shanhai pass's Hun Guo, shadow carving, Qinglong tofu, Funing embroidered shoes and other experiential, if the experiential packaging design are processed to develop it as tourism products, experiential elements are fully integrated into its production process, technology and cultural, which will bring huge economic benefits. The traditional folk music and dance as Changli To Yangko, Funing wind and drum music, through designing choreography, performed by the inheritors, the total sensory experience of visitors can be greatly enhanced, so that the tourists immersed in the strong atmosphere of traditional art and actively involved in tourism projects. Through experience, the tourism process have impacted Tourists deeply, and enjoy a hearty feast of culture. Because of the intangible cultural heritage of highly personalized, inherited experiential and concentrated ethnic, once combined with tourism development, the strong vitality could erupt, which is great to meet a higher level of travel demand of tourists, greatly expand the connotation and extension of tourism resources.

\section{B experiential tourism development role in promoting the protection of intangible cultural heritage}

Protection and Inheritance is the background and purpose put forward by the "intangible cultural heritage" concept. The core and essence of protection of intangible cultural heritage is heritage and development. Simply through the museum-style protection can only provide tourist with lifeless 
body, and fail to express their inner spirit, not to mention heritage and development, will eventually become extinct. Since the intangible cultural heritage has a living transmission characteristic by communication between people, scientific tourism development is more conducive to provide efficient protection for intangible cultural heritage, the utilization and development are necessary pathway to promote the protection of intangible cultural heritage. Tourism is essentially a cultural activity, with its own features like inheritance, development and protection of cultural, through tourism development to protect social cultural environment suitable for survival of the intangible cultural heritage reasonably and moderately, activate its function and restore its own function, which can remain active state of intangible cultural heritage in the true sense. Such as the "Chinese red wine town" Changli, a unique taste of red wine tour in Qinhuangdao is developed, visiting Asia's largest wine cellar, modern wine storage workshop, imported automatic filling production line, picking grapes, wine tasting, which makes visitors personal experience the charm of wine culture. Through the rational development and utilization to transmit intangible cultural heritage into a culture carrier with living state, so as to attract more tourists come to experience, combined with the advertising of the intangible cultural heritage by local tourism sector and tour operators as well as communication with others, tourists can gain a profound understanding of value and significance of intangible cultural heritage, and thus enhance the sense of responsibility for protection, so as to achieve the purpose that protecting the intangible cultural heritage from top to down.

\section{C problems for intangible cultural heritage protection caused by tourism development}

The intangible cultural heritage documented folk culture and traditions formed in the long-term production of people in the form of person communication, compared to tangible cultural heritage is more fragile and non-renewable, driving by the maximization of economic interests, there are some behaviors of quick success indeed exists in tourism activities, the phenomenon that the traditional culture is made into vulgar, and over-commercialization, wanton tampering authenticity of folk in order to cater to the tastes of tourists, misinterpreted the connotation of intangible cultural heritage, or in order to seek immediate economic interests at the expense of damaging the current traditional heritage, which making the traditional simple folk and sentiments gradually fade, alienation and even disappear. Currently the boom of "declare for intangible cultural heritage”, in part, only cares about the economic value of cultural heritage value and advertising effect of local publicity, just put it as a "cash cow", and lack of adequate importance for heritage protection. In addition, with tourism activity continues to heat up, the number of visitors grew overload, the local natural environment has been polluted and destructed of a certain degree. Tourists' behavior may change the local folk customs. Have to say, to some extent, development and protection are contradicting with each other. Therefore, protection and vitality for continuing of the intangible cultural heritage rely on person themselves, is relatively fragile and difficult. During the development of intangible cultural heritage as tourism projects, there points should be paid more attention in particular.

Therefore, the rescue and protection of intangible cultural heritage is imminent, but the core of protection is heritage and development, rational development and utilization is the only way for heritage. Scientific and rational tourism development is an effective way for protecting intangible cultural heritage.

\section{Protection strategy for intangible cultural heritage based on experiential tourism development}


Exploitation is to go the path of market-oriented to develop the potential economic value of intangible cultural heritage, so as to solve space problems of its presence and heritage with tourism market, which is the best choice for the effective protection for intangible cultural heritage. If an equilibrium point and rational mode can be found between tourism development and heritage protection, and correctly handle the relationship between tourism development and cultural protection, it will greatly promote the development of tourism, and also enable the intangible cultural heritage to maintain the original vigor and vitality, experiential tourism development is regarded as an effective way for intangible cultural heritage protection, so as to achieve benign interaction of tourism development and intangible heritage protection. Qinhuangdao municipal government and tourism management department attaches great importance to the protection and development of intangible cultural heritage. But still there are some problems in development, for the current situation of intangible heritage tourism development in Qinhuangdao, a few policies are provided for intangible cultural heritageprotection based on experiential tourism development

A tourism development for intangible cultural heritage should focus on maintaining its original true state trait

Intangible cultural heritage is produced in certain regions, living on their cultural soil, the original true state is the unique gene, leaving a unique geographical conditions means losing of the soil for survival, and therefore the unique cultural background of intangible heritage cannot be ignored during the tourism development, deceitful or concentrated the intangible cultural heritage into one place for displaying means violating the basic principles of its original ecosystem, which may lead to the end. Therefore, when developing the intangible cultural heritage, have to root in ecological environment of the local culture, only to integrate intangible cultural heritage into the local natural and cultural environment can maintain itsoriginal authenticity and provide the best travel experience for tourists.

$B$ increase the mining of the connotation of intangible cultural heritage, exhibit "true soul" during the development

An important feature of the intangible cultural heritage is its distinct region. During intangible cultural tourism development at Qinhuangdao, the exploring for cultural connotations like the origin, the history of the development and unique playing skills of intangible culture is insufficient, indifferent and extensive development concept often make the intangible cultural heritage stay in the external form, without the connation, which provides the tourists with incomprehensive concept. Culture is the spiritual connotation of tourism, the profound cultural spirit of the intangible cultural heritage must be excavated in depth, which can make it without losing the "true soul." As Qinhuangdao Lulong County known is the "hometown of Chinese Guzhu culture ", the famous historical story of Bo $\mathrm{Yi}$ and Shu Qi is circulating. Guzhu cultural theme park is built to demonstrate Guzhu culture, eight cultural and natural landscapes of ancient Lulong county are concentrated here, then Flower-Picking Song, Don't eat Zhou Su and other allusions are integrated into the landscape, plus a large history musical "Guzhu grand song", highlighting the strong regional characteristics, which take visitors into the dusty, ancient Guzhu State, clearly touched Guzhu culture, have profound experience of humble, selfless, personal dependence, not give up to die of Bo Yi, it is a good paradigm with both external and spiritual form of tourism development for intangible cultural heritage. 

development

Today, with the continuing abundance of tourists' experience, tourists have been unwilling to accept a passive quick walkthrough form of tourism, more willing to take the initiative to perceive, experience and participation. Experience and leisure of travel has become a craze for contemporary tourists to chase. Travel experiential activities have become increasingly personalized and emotional. While intangible cultural heritage is the presence of a typical living state with rheological characteristics. It needs to live on national geographical characteristics during the tourism development, rooted in its unique production and lifestyle, highlighting the national character and aesthetic characteristics. Therefore, in the development of the intangible cultural heritage, the leisure of experiential tourism is its core, with the means of expression like sound, image and artistry, and full integration of tourists initiative, participation, emotion, can better reflect its continuity "live" as a regional culture in.

However, in the current tourism development of intangible cultural heritage in Qinhuangdao, experiential tourism projects are often absent and at a lower level. In this regard, in the tourism development, deep experiential projects with strong participation should be designed in a large quantity, including traditional art performances and interaction, dining experience, folk crafts, experience production process and other, such as Special Diet culture in the intangible cultural heritage at Qinhuangdao, its historical background, origins, folklore, etc. can be explored, taste, experience and production process can be included into tourism projects, allowing visitors to listen, watch, and taste in dining environment having the characteristics of folk, feeling food culture with strong ethnic local characteristics. At the same time, by this type of tourism of deep experience, tourists is aware of the intangible cultural heritage at close range, and strengthen the tourists' experience of intangible cultural heritage, to further enhance awareness of the protection of intangible cultural heritage, truly achieve the protection of intangible cultural heritage.

D Combined with the individual needs of tourists to expand the tourism product type of intangible cultural heritage

Experiential tourism focus on the personality and emotional needs of tourists. Different tourists have different perception and involvement to cultural atmosphere and living habits, which need to expand the tourism product type of intangible cultural heritage. According to Qinhuangdao intangible cultural heritage tourism resources types and deep-seated need for humane touring of tourists, the following product types can be expanded, such as:

1) The new Folk Museum: change the past simple display, using modern means like sound, light, electricity to reflect local customs environment, handmade, playing skills, etc., to reproduce the true state of its original environment;

2) Folk Culture Village: rooted in the unique cultural soil of intangible cultural heritage to establish the original eco-style Folk Culture Village. The local villagers as the owner and operators of Culture Village can provide visitors with experience of authentic atmosphere with the full range characteristics of folk.

3) Virtual Stage Performance: The huge success of Zhang Yimou's Image series is a good example for combining the natural landscape resources and intangible cultural heritage. With the natural landscape as a carrier, highlighting the essence of the local culture folklore. Experience of tourists can be greatly enriched from the senses. 
4) The featured folk industry: utilized to showcase folk arts and crafts with Qinhuangdao characteristics, after packaging, the cultural industry is formed, such as processing skills of Beidaihe Yang Chang Zi, folk industries of Funing embroidered shoes and so on.

\section{References}

[1] Li Xingming, Zhang Chunli. Conception research of Intangible Cultural Heritage [J]. For um on Chinese Culture, 2007, (2): 99-101.

[2] Duan Lei. On the Tourism Development and Protection of China's Intangible Cultural Heritage [J]. Enterprise Herald, 2011, (17): 56-58.

[3] Lian Hongyu. Research on Protective Tourism Development of Intangible Cultural Herita ge - A Case Study in Chengdu. Economic Research Guide, 2011, (24): 186-188

[4] Liu Song, Ma Jingqing, Lv Dongyang. Research on Changzhou Intangible Cultural Herit age Tourism Development [J]. Northern Economy, 2009, (8): 58-59

[5] He Xuejun. Theoretical thinking of Intangible Cultural Heritage [J]. Jiangxi Social Scien ces, 2005, (2): 103-109. 